OSCAR TACCA

\title{
SARMIENTO Y LA REVOLUCIÓN FRANCESA
}

\section{1.- El siglo de las luces, los gozos y las sombras}

Quienes prepararon la revolución más importante, la que abre precisamente la Edad Contemporánea, no hablaban de revolución. Los pensadores del siglo XVIII inquietaron las conciencias, denunciaron las falacias de un orden ético y social plagado de contradicción e injusticia. Pusieron en evidencia el privilegio, la corrupción y el abuso, en suma, la ipracionalidad de la organización social y la opresión del Estađó. Pero la idea de "revolución" en su alcance social, o más bien político, en tanto el Estado es la expresión genuina del edificio social, no aparecía en ellos.

Era, aún, la utopía. No obsta para que aquel espíritu de examen (especialmente manifiesto en el Contrato social y en el Origen y los fundamentos de la desigualdad de los hombres) fuese la caja de Pandora -como dice Raúl Orgaz- "de don de escaparon, a los cuatro vientos, todas las ideas que han envenenado la atmósfera social europea" (1). Para decirlo con palabras de Sarmiento: "se levantaba un monstruo nuevo en la familia de las herejías, que no tenía nombre ni cabeza".(III, 262) (2).

Hacia mediados del siglo, sin embargo, las ideas de rei vindicación y justicia estaban ya "près de la victoire", como titularía Paul Hazard el último capítulo de su conocido ensayo (3). "Casi toda Europa ha cambiado de rostro desde hace cincuenta años" escribía Voltaire en su Tratado de la Tolerancia. "Después de 1760 , Europa parece conquistada, y la par tida ganada" sostiene Hazard. La Razón (entonces siempre es- 
crita con mayriscula) se habfa impuesto, los filósofos auguraban una era dichosa: "los reyes son más tolerantes que nunca; surge una generación que se horroriza del fanatismo; las primeras funciones serán un día ocupadas por los filósofos, nues tro reino se prepara, de nosotros depende su 1legada" glosa y sintetiza Hazard (4).

Estos filósofos no eran ni violentos, ni declamatorios, ni ergotistas. No se parecian ni al estoico, ni al monje, ni al cortesano, ni al erudito. Eran hombres que procuraban aliar su pensamiento al goce de la vida, las ideas a la práctí ca, la Razon a la Felicidad.

Al estudiar el mecenazgo que los déspotas ilustrados brindaban a los escritores, el minué de las "reverencias de los príncipes a los filósofos y de los filósofos a los prínci pes", Hazard señala que los filósofos se engañaban: "El defec to estaba en que la filosofía creía servirse de los reyes y eran los reyes los que se servían de ella". Era verdad. Pero Sarmiento, a partir de aquella misma observación, (que todos estaban convencidos de que la libertad y la igualdad serian un bien comín cuapdo la filosofía reinase en el mundo), con mirada prospectiva llega a otra conclusión: "tan convencidos llegan a estar todos de que esto es la cosa más natural y sen cilla del mundo, que el rey, los cortesanos, los príncipes, los nobles, los obispos, los abades y los frailes, tenedores todos ellos de los privilegios y de la mayor parte del territorio, son los primeros filósofos, los primeros revolucionarios, los primeros propagadores de las doctrinas más subversi vas y desquiciadoras, de tal manera que hoy se han acumulado los desencantos de un siglo, y pocos hallan sorprendentes las profecías de Cagliostro y otros iluminados, que anunciaron la triste suerte que les agurdaba, aplastados por las ruedas del mismo carro que con tan poca destreza echaban a rodar." (XXXV II, 257).

La organización social, sin embargo, no iba por el mismo camino ascendente de las ideas intelectuales y morales: an tes bien, las condiciones materiales del pueblo empeoraban a medida que avanzaba el siglo, y Sarmiento confiesa la sorpresa de que "Voltaire, demoliéndolo todo con el arma francesa 
del ridículo; Rousseau, enseñando los medios y método de parar de punta una pirámide" no hubieran conducido a un cambio. Y recuerda que Buckle se asombraba "de que el pueblo francés hubiese podido tolerar hasta la revolución de 1789 el infame, monstmoso gobierno que lo había reducido a la condición de bestia de sembrar trigo", y de que Taine revelara "que los nueve décimos de los municipales de Francia entonces no sabían leer, porque pocos poseian tanto saber." (XXXVII, 252)

Así, superada la hambruna de 1709, "la época de los filósofos fue un período de gran prosperidad, en el que las riquezas regaron la vida francesa" como dice Mandrou (5), hasta llegar a la seria crisis prerrevolucionaria.

El siglo que culmina con la gran convulsión de la Revolución Francesa representó, no metafórica sino realmente, esa progresión del acápite: iluminación y holgura en el comienzo y la mitad de la centuria, sombras y crisis en el final. 


\section{2.- Todas las revoluciones, la Revolución}

La historia no se repite. Pero si se repite. Ortega recuerda que Schopenhauer decia con humor que "la misión de la historia estaba en mostrar cómo las cosas han sido siempre las mismas, sóló que en cada momento de otra manera: eadem sed aliter". (6). Una misma ésencia, cada vez con diferente rostro. Por lo primero se ha dicho que la historia es maestra de la vida; por lo segundo, que es necesario interpretarla. Pero la humanidad rara vez lo hace, y de ahi sus desgracias repetidas. Sólo unos pocos descubren lo permanente a través de 10 transitorio. Sarmiento era escéptico respecto de ese don de penetración: "las citaciones de la historia -deciason inútiles para el público: él no se reconoce nunca en el drama en que los personajes figuran siempre con diversos nombres, las pasiones humanas, y las ambiciones." (LII, 32)

¿No ocurre algo de esto con las revoluciones? Pero ante todo ¿qué es una revolución? La teoría registra interpretacio nes que van desde su concepción como un estado de espíritu hasta un morbo, desde una resurrección hasta la socialización de un escándalo. ¿Cúando tiene lugar? Cuando hay un desconten to colectivo intolerable. Y ¿cuál es la esencia del fenómeno revolucionario? Habría, segín Orgaz, una esencia espiritual, cuyo conocimiento resulta indispensable para la determinación de su esencia social. Existe, pues, un perfil sicológico y otro sociológico del fenómeno revolucionario. Pero la insatis facciónde orden sicológico debe encontrar resistencia (en otro grupo) y traducirse en malestar sociológico para que haya revolución. El grupo de la mencionada insatisfacción (masa) debe albergar en su seno, sin embargo, una minoría esclarecicla (élite).

La praxis de la revolución, por su parte, muestra que la acción de escritores y filósofos genera la conciencia social propia de los períodos prerrevolucionarios. Esta concien cia incide de una manera decisiva en la pérdida de confianza en el estado de cosas anterior, de los grupos dominantes. Apa rece un marcado escepticismo y una debilitación de las defensas. "Son los magistrados mismos los cómplices de los filóso- 
fos contra la autoridad que representan, y muy pronto es elegante menospreciar los prejuicios, la superstición y el fanatismo" dice el historiador Mornet (7). En fin, aquella conciencia social va a ser el teatro del conflicto, en su etapa propiamente revolucionaria.

Entonces, la utopía ya no basta: la inteligencia convoca al sentimiento, y tras la voluntad, a la pasión.

$Y$ sin embargo, no todos los conflictos han merecido el carácter de revolucionarios en la historia del hombre. Conoci do es el diálogo de la Rochefoncauld con Luis XVI después de hacerlo despertar en la noche del 14 al 15 de julio para anun ciarle la toma de la Bastilla (y con el que Taine abre precisamente el tomo respectivo de su Historia): -Entonces es una revuelta, dijo el rey. -Majestad, respondió el duque, es una revolución.

Orgaz afirma en su ensayo: "Conviene prevenirse contra el error de confundir cualquier cambio institucional, por extensa y profundo que sea, con un genuino proceso revolucionario" (8). Albert Camus, al indagar el verdadero carácter de las revoluciones históricas, señalaba: "Un cambio de régimen de propiedad sin el correspondiente cambio de gobierno no es una revolución, sino una reforma" (9).

Sarmiento mismo se veía en la necesidad, hacia 1875, de precisar el concepto, pues constataba que "no hay movimiento subversivo, por pequeño que sea, ni motín de un cabo con cuatro soldados, que no llamemos genéricamente revolución" (XXXIX, 30). De ahí su desprecio por lo que "llaman revoluciones los mismos que las prohijan, y se figuran ennoblecerlas con palabra que reputan noble y aceptada" (XXXIX, 197).

El abuso del vocablo lo indignaba, y quería proscribirlo de nuestro idioma político; no cabía en un estado legal. Recordaba que desde el día en que "Mitre empuñó el bastón de Presidente y ciñó la banda de generalísimo de la República, la palabra Revolución quedó borrada del diccionario legal, quedando sólo consignada en la pasada historia, en caracteres de oro, pues como lo hemos mostrado, la revolución nacional contra las tiranías que eran obstáculo a dar una Constitución, principó y acabó con este santo propósito" (XXXIX, 30). 
Y agregaba: "La Constitución dada entonces y vigente hasta hoy, excluye la palabra revolución, sustituyéndole las palabras legales, insurrección, conmoción, invasión, todos crímenes definidos y castigados" (ib.).

El fragor del combate no es indispensable para que un proceso adquiera el carácter de revolucionario. Quizás hubo revoluciones que se hicieron sin que sus protagonistas tuviesen plena conciencia de que las hacían. Por eso lamentaba Julián Huxley: "Es tal vez una lástima que la palabra revolución tenga dos sentidos: uno de insurrección, el de levantamiento sangriento contra la autoridad constituida; otro, el de un cambio tajante y de grandes proporciones en las ideas e instituciones que constituyen el armazón de la existencia humana" (10).

Pero si bien es cierto, como indicaba Ortega, que "no todo proceso de violencia contra el Poder público es revolución" (11), no es menos cierto que el ingrediente de la lucha y el combate rara vez está ausente, al menos en la historia moderna, y que lo que varía es el mayor o menor grado de disturbio, de violencia o de terror. La humanidad parece haber consagrado más bien que no hay revolución sin sangre, y lo que la caracteriza es la mayor o menor abundancia con que ha corrido. 0 tal vez -paralelamente aunque no siempre proporcio nalmente- el grado de horror con que se la ha visto correr.

Admitamos, entre tanto, la distinción entre revolución pacífica y violenta, o, como simplificaba Echeverría, entre revolución de hombres y revolución de ideas. (Curiosamente, la palabra, que en su etimología original aludía únicamente al movimiento, en especial de rotación, y sólo en sentido figurado fuera utilizada -ya hacia 1455, según el Diccionari Aguiló- para referirse a un movịmiento subversivo, invierte esa relación modernamente, pareciendo hoy indudable que el lenguaje comin asigna al concepto de revolución el sentido recto de violencia, y sólo metafóricamente lo conserva al hablar de revolución industrial, estética, moral).

La revolución politica o social, sin embargo, es tanto de hombres como de ideas. En todo caso, el interrogante consistiría en determinar el verdadero orden de prelación (en la 
posibilidad de establecerlo). 0 sea, si el orden es el de la utopía primero y la acción después, si estalla antes en las cabezas que en la calles, o al revés. Raúl Orgaz, en su mencionado ensayo, afirmaba en sfintesis que "el alma revoluciona ria entra en los paraísos de la utopía (...) pero porque antes ha pasado por el infierno de la historia viviente" (12). Camus, en cambio, después de hacer el proceso de todas las re voluciones, sostenía que "la revolución comienza a partir de la idea $(\ldots)$, es la inserción de la idea en la experiencia histórica (...), una tentativa de modelar el acto sobre una idea" (13).

En fin, lo cierto es que, aunque las revoluciones se ja lonan en la historia por su estallido político y social (en la misma proporción de su violencia), su verdadero alcance queda signado por los principios que las preceden o las ideas que se derivan. Dicho de otro modo, por la utopía prerrevolucionaria o por el nuevo orden. Aunque lo que se conmemora es la toma de la Bastilla, la revolución reside en la Enciclopedia $y$ en los Derechos del Hombre y del Ciudadano. Por lo demás, de un planteo rigurosamente histórico se proyecta a un enunciado atemporal y ecuménico: "La Revolución se inicia negando los privilegios del noble francés del siglo XVIII, y acaba proclamando los derechos del hombre" (14).

De esa ecuación nacen los controvertidos juicios y pronósticos sobre su realidad. Taine profetizaba que no habría ya otra Revolución Francesa en Europa, Ortega negaba que hubiesen tenido lugar en América, Camus afirmaba que no las había habido aún en la Historia.

La historia, sin embargo, ha retenidounas cuantas, "ejem plares": la revolución inglesa, la francesa, la norteamericana, la rusa... La cuota de violencia o de terror, como se ve, varía considerablemente. En todas hay siempre una "pars destruens" y una "pars edificans", un rechazo y una afirmación, un combate y una mística. Octavio Paz decía: "Toda revolución es, al mismo tiempo, una profanación y una consagración" (15).

Sarmiento se ha referido constantemente a las revolucio nes, y su juicio ha provenido esencialmente de la estimación de los términos del conflicto, de una evaluación ética, siem- 
pre ligada a su horror visceral por la crueldad y la barbarie. No es extraño entonces verlo exaltar a la revolución inglesa (que, recurriendo a Macaulay, llama defensiva), la cual, por un camino menos cruento, de "evolución", llega a los mismos resultados de las revoluciones violentas y al mismo calificativo de gloriosa. Trevelyan dice que "quizás hubiera sido más apropiado llamarla la Revolución Sensata, lo cual la distinguiría más claramente de las ot́ras revoluciones" (16). Distin ción que André Maurois sintetiza en su Historia de Inglaterra, explicando que alli "no se habían formado entre la aristocracia terrateniente y los granjeros, entre la corte y los comerciantes de la City, los vigorosos odios que provocan las castas cerradas. La desigualdad era grande, pero las carreras se hallaban abiertas al talento y las leyes se aplicaban para todos" (17). Para Maurois, los ingleses sintieron una benevolencia optimista por la Revolución Francesa desde $17 \overline{9 \text { hasta }}$ 1792, que se transformó en declarada hostilidad ante la ejecu ción de Luis XVI y la ocupación de Bélgica; Sarmiento lo hubiera acompañado en esta interpretación.

Junto a la revolución inglesa, hacía la invariable ponderación, naturalmente, de la norteamericana, hecha por unos labradores que agredidos en su derecho "habían abandonado el arado, y reunidos en ejércitos de voluntarios, vencido las es cuadras y los ejércitos de Inglaterra, para volver a su trabä jo ordinario en seguida" (III, 262).

Crane Brinton ha hecho una radiografía de las cuatro re voluciones más conspicuas de la historia moderna (las que ya hemos mencionado), para descubrir la anatomia de la revolución (18). Por encima de sus rasgos peculiares, destaca las uniformidades. Todas ellas pretenden cambiar un injusto estado de' cosas, que puede recibir' genéricamente el nombre de "antiguo régimen". Son los síntomas procrónicos, que revelan una sociedad enferma.

A ellos les siguen las tres etapas características del cambio revólucionario. La primera, de los estadios iniciales, pasa por las fases sucesivas del relativo auge económič, los antagonismos de clase, la deserción de los intelectuales, la insuficiencia del aparato gubernamental y la ineptitud de la 
antigua clase dirigente. Simultáneamente, aparece la incapaci dad de la autoridad para hacer uso de la fuerza. Al triunfó sucede el reinado de la Virtud, o de la Religión, o de la Mís tica. La segunda es la del Terror, en que un grupo relativamente pequeño monopoliza la acción, imponiendo la violencia, y haciendo que el hombre comín se sienta inseguro, sujeto al "gran temor". La tercera puede ser designada con el nombre co mún de "reacción termidoriana", etapa de convalecencia en lá que surge el tirano, con un "retorno de la iglesia". Ortega hablaba de decadencia, en su epílogo sobre el alma desilusionada (19).

En fin, para Brinton, todas las revoluciones obedecen a un mismo proceso esencial, el de la Revolución. También Sarmiento entreveía esa unidad, al hablar del derecho popular de revolución, sus causas y sus límites, sosteniendo que "aquí es el lugar de señalar un rasgo que une entre si todas las grandes revoluciones de los pueblos desde la caida de los Estuardos en Inglaterra" (XXXIX,24) y que no era otro que el re clamó de representatividad y división de los poderes. 
La influencia de la Revolución Francesa en América ha sido tema controvertido. Algunos han negado su eco en estas orillas, y un reconocido historiador ha escrito que " en nada influyó en la independència americana". La opinión es rechaza da por otros. En ocasión del, $150^{\circ}$ aniversario de la Revolución Francesa, la Academia Nacional de la Historia le rindió homenaje con un acto en el que, tras las palabras de apertura del Dr. Levene, a la sazón presidente, hablaron el embajador de Francia para referirse al hecho, y Ricardo Caillet-Bois pa rà exponer sobre la América española y la Revolución Francesa. En esa disertación -recogida luego en el Boletín (20)sostiene el historiador que la influencia existió, y que, al margen de su magnitud, los estudios modernos han ido poniéndo la en evidencia. En apoyo de su afirmación, reseña la cambian te repercusión que la noticia de los hechos fue cobrando en América, desde la favorable acogida inicial hasta la adversa opinión provocada por la ejecución de Luis XVI. "Partidaria o no de la ideología de 1789 -dice el autor- la sociedad colonial sufrió una vérdadera conmoción como no la había experimentado hasta ese momento, ni aún cuando los norteamericanos de Norteamérica sacudieron la dominación europea en 1776". "Los colonos -añade- salieron del marasmo en que se hallaban sumidos, analizaron su situación con respecto a España y, pau latinamente, insensiblemente, fueron formando un núcleo de opinión independiente". Y concluye: "En 1800 se había progresado en forma insospechada. Por entonces los virreyes vivían desconfiados e inquietos. La revolución golpeaba ya en las puertas del vetusto edificio."

Tampoco fue pareja la intensidad con que recibieron la influencia las posesiones hispánicas. Caillet-Bois la analiza en el virreinato de Nueva España, en las capitanías generales de Guatemala, Cuba, Venezuela, Chile y en la Presidencia de Quito, hasta llegar a los virreinatos del Perú y del Río de la Plata en que la influencia fue más débil por estar más ale jados del teatro de las operaciones.

En el último, sin embargo, se vigilaba a los barcos que 
1legaban de Europa, como ocurria en Montevideo en diciembre de 1789 con la corbeta Duque de Orleans,para comprobar si no "esparcía líbelos ó Papeles concernientes á la actual situación de la. Fráncia". Mientras tanto, parece ser que los franceses que vivían en Buenos Aires y los criollos expresaban su beneplácito por la reunión de los Estados Generales. Un bando del $1^{\circ}$ de marzo de 1790 prohibía la difusión de pasquines y papeles sediciosos.

No es extraño que así ocurriese, cuando Sarmiento da cuenta de que aún las ideas del siglo XVIII eran censuradas, como lo dice en un extenso párrafo que por su ilustrativo contenido vale la pena transcribir: "No había sermón sin San Agus tín, y los nombres de Voltaire, Rousseau, Diderot recibían de cada predicador su maldición condigna, con lo que se despertaba la curiosidad de los estudiantes y los sobrinos de los cu ras lograban con sus importunidades que entre casullas y capas de coro, misales y breviarios que no habían de ser registrados en la aduana, por especial privilegio que aún subsiste, se introdujese la Enciclopedia cuan voluminosa es, y existió en América por centenares de ejemplares y las obras de Voltaire y las de Rousseau eran del dominio público, como lo revela el he cho de haberlas quemado el padre Piñero en auto de fe en $187 \overline{8}$ en el Colegio Nacional de Santiago del Estero, donde las encon tró, no siendo de data reciente su introducción, pues hacía cá si un siglo que no eran material de lectura, salvo la Nueva Eloísa y el Contrato Social." (XXVIII, 200)

Y si esto sucedía con los filósofos ilustrados, cuánto más no ocurría con las noticias y libelos de la Revolución: "Pero qué decir, como instrumento contundente, punzante, cortante e hiriente de educación, de la revolución francesa que desarrollaban sus cuadros grandiosos y aterrantes hasta ver sa lir de aquella fulguración incesante la Gran Bestia del Apocalipsis (así nos lo decían) llevando la desolación a los cuatro extremos de la tierra." (ib., 201)

Es más. Sarmiento llega a descontar la incidencia de aquellos acontecimientos en el aprendizaje del francés en estas tierras: "la refulgencia de la revolución francesa y las gloriosas batallas de Bonaparte transformado en Napoleón, que 
las hacia trascendentales a la América del Sur, hizo popular el conocimiento del francés en las clases inteligentes por toda América con el que se aprenderá a leer entonces para saber lo que ocurría, se decía, esperaba o temía." (ib., 201)

Leyes y bandos estipulaban severísimas disposiciones pa ra impedir el ingreso y difusión de las noticias y de las ideas que sostenian los revolucionarios franceses. A pesar de ame nezas $y$ castigos, la vigilancia era burlada. Innumerables hechos lo prueban. Pero la propaganda llegaba a los habitantes, especialmente a los criollos y extranjeros residentes que expresaban su satisfacción por la reunión de los Estados Generales. Libelos, copias manuscritas de discursos, cartas, daban cuenta de los sucesos revolucionarios, y corrían entre aquella parte de la población más desahogada e instruida. Con la mayor vigilancia cundía el interés, y con éste la circulación clandestina de papeles sediciosos, medallas, monedas, hasta ser bien conocidos los nombres de algunos protagonistas como Robes pierre. La difícil situación de la monarquía española favorecía las ideas de libertad, y comenzaba la inquietud de las autoridades ante yeladas reuniones, algunas realizadas en la quinta de Liniers. Hubo un proceso a negros y franceses acusados de conspiración. Lo mismo ocurría en Montevideo donde al parecer los esclavos, bien relacionados con los de su clase que navegaban por el río de la Plata, hacían temer una subleva ción.

Si esto sucedía con la población de las diversas clases sociales, es de imaginar en qué medida las nuevas ideas ganaron la conciencia de los prohombres de la emancipación rioplatense.

Caillet-Bois 10 muestra en algunos. Belgrano, por ejemplo, recuerda en sus memorias la repercusión que aquellas ideas tuvieron en los hombres de letras que entonces frecuentaba en España, y que le hicieron abrazar los ideales de libertad, igualdad y propiedad, llegando a ver sólo tiranos en quienes se oponían a tales derechos concedidos por Dios y la naturaleza.

En cuanto a Moreno, rescata el hecho de que hiciera edi tar una traducción del Contrato Social, con un prólogo encomio 
so, así como su prédica inspirada en los girondinos. De Montea gudo, a su vez, transcribe un párrafo en el que su autor destá ca la influencia de las revoluciones norteamericana y francesa en las colonias españolas, despertando el espíritu de resisten cia, anticipo de los movimientos independizadores. Agrega Monteagudo que su adhesión lo había llevado a "abrazar con fanatismo el sistema democrático", hasta parecerle insuficiente el Contrato Social. En las proclamas de San Martín, finalmente, Caillet-Bois encuentra el eco del credo revolucionario que ins pirase las grandes transformaciones políticas e institucionales para restablecer los derechos de la especie humana. 


\section{4.- Sarmiento y la Revolución Francesa}

Sarmiento se refirió en numerosas ocasiones a la Revolü ción Francesa, y esas referencias quedan registradas a lo largo de sus artículos y discursos. No obstante, si se sumaran to dos los reparos, las críticas y las objeciones con que cada vez alude a ella, se llegaría $a_{i}$ la conclusión de que son mayores las reservas que el elogio franco. Pero digámoslo desde ya: es que para Sarmiento la Revolución Francesa era un valor entendido. Sería necio atribuirle un pensamiento general basado exclusivamente en sus criticas y reparos. Tal hipótesis constituiría una miope argumentación, que quedaría desvirtuada por él mismo cuando recurre precisamente al ejemplo de la Revo lución Francesa ante un caso similar. En efecto, al comentar un artículo sobre el Romanticismo aparecido en el Semanario (Mercurio, 25-7-1842), que con escasa inteligencia y menor. pon deración evaluaba dicha escuela únicamente por sus notas negativas (inverosimilitud, defecto, extravaganoia, "todo aquello, en fin, que es contrario a la razón, a la naturaleza y a la verdad") Sarmiento afirma que si el mismo criterio se adoptara para juzgar a la Revolución Francesa, ésta no sería más que "el desenfreno de las pasiones más abominables, el robo, el de guiello, la impiedad, la depravación de las costumbres, la aniquilación de todo principio moral. Porque en ella se vieron las matanzas de setiembre, las noyades, las metralladas, la guillotina ambulante, Robespierre, Marat, la conquista a sangre y fuego, y el saqueo de las ciudades y los excesos de una soldadesca victoriosa" (I, 287)

- Para Sarmiento, la Revolución Francesa era el acontecimiento "que ha cambiado la faz dẹl mundo". Vale la pena ver, sin embargo, en qué se fundaron sus reparos. Pues el verdadero homenaje consiste en el conocimiento acendrado de la verdad histórica, es decir, tanto en los aspectos estremecedores del Terror como en los principios de justicia e igualdad que consa graron definitiva y universalmente los Derechos del hombre $\bar{y}$ del ciudadano.

¿Fue Sarmiento más sensible a los detractores que a los panegiristas de la revolución Francesa? La visión que de 
ella posee lo induce a reservas que radican en tres cuestiones fundamentales, a saber, la violencia, el populismo y la deriva ción inmediata de la revolución (Napoleón).

Sarmiento, por de pronto, tiene clara conciencia de la diferencia que existe entre la revuelta (o motín) y la Revolución "como el gran crisol en que se depuró una Nación". Viene al caso recordar aquí la doble faz de toda revolución, su cara y ceca. "¿Qué es un hombre rebelde?" se preguntaba Camus, para responder: "Un hombre que dice no. Pero aunque rechaza, no renuncia: es también un hombre que dice si, desde el comienzo" (21). Por eso toda revolución destruye un orden y construye otro. Son la "pars destruens" y la "pars edificans", los pro cesos de muerte y resurrección de los que hablaba Orgaz. Pero am bas varian, y si la segunda lleva tiempo, la "pars destruens" puede ser violenta y breve, hasta alcanzar el indice más alto de la escala sísmica. El aniquilamiento del orden anterior entraña muerte y destrucción, una violencia y una crueldad que pueden llegar al paroxismo. Allí están, durante la Revolución Francesa, las matanzas de setiembre, la guillotina, el río de sangre. Sarmiento fue especialmente sensible a esta "eficacia" que en su pensamiento tenía un viejo nombre: la barbarie. Por eso, una y otra vez exaltará el programa y condenará los hechos de la Revolución Francesa, mediante el repudio de "los adoradores fanáticos de sus horrores más que de sus principios" (XXXI, 254)

Esa condena se acentuará con los años. Quedarán atrás los miramientos e indulgencias. Los había tenido cuando hablaba de los excesos de la Revolución de Mayo "amenazada de perecer sofocada en su cuna y que llevan esa grandeza solemne que denuncia el Hércules niño, destrozando serpientes con sus mane cillas", o cuando evocaba a Moreno, el "Danton de la revolución americana", diciendo que "sabía arrojar como una granada esas grandes medidas revolucionarias que la moral condena y la razón desaprueba, pero que salvan una revolución y engendran naciones nuevas, y nuevo espíritu, arrasando obstáculos, no im porta que estos sean hombres" (VI, 55). O cuando hablaba de lá Francia de su tiempo, "indulgente todavía en mucha parte con los antiguos excesos del patriotismo" (XLVI, 296). Con el tiem 
po fue enfatizando a ponderación de las revoluciones inglesa y norteamericana, en que la "pars destruens" era menon, y anatematizando a la francesa por sus olas de intolerancia $v$ de furor.

Habría que decir aquí que, seguramente de modo conscien te y subconsciente, obraba en Sarmiento la asimilación de una violencia a otra: la de los Marat, los Danton y los Robespierre a la de Rosas. Y esta identificación es la que enardece su ver bo: "No era necesario que Rosas leyese libros. Estaba en la at mósfèra americana el prototipo aquel del gobierno criminal en nombre de la justicia, la tiranía para hacer triunfar la liber tad, la sangre para fecundar los derechos del pueblo." (XXVII, 326)

El ardor de la lucha contra la tiranía lo lleva a paran gonar el régimen con los aspectos que consideraba más nefastos de la Revolución Francesa: "Rosas -dice- es la parodia de Robespierre y de Marat, con su club de los Jacobinos (la mashorca), el furor popular (faubourg Saint Antoine), la cinta colorada (el gorro frigio), las matanzas de Setiembre, la liberté ou la mort -Mort aux aristocrates!" (XLVI, 296)

El demonio de las comparaciones, por parte del gobierno francés (ministerio de Guizot), con sus simplificaciones lo ha bía exasperado durante su estada en Francia. Resumía: "Rosas' Luis Felipe. La mazorca $=E 1$ partido moderado. Los gauchos $=$ La petite propriété. Los unitarios = La oposición del National. Paz, Varela, etc. = Thiers, Rollin, Barrot." (V, 124). Ahora (1859) él también ejercía la propia. Sin embargo, su entrañable esquema de civilización (la ciudad) y-barbarie (el campo), no se avenía demasiado, naturalmente, con la Revolución, que se incuba y estalla en la Gran Ciudad de Europa. Pero Sarmiento, como de costumbre, no se arredra, y recurre a otros enfoques, útiles (aunque no menos forzados) para sustentar el correlato: "detrás de nuestros ejércitos de línea se en cendió una guerra de 1 vendée, por las mismaa causas y con los mismos chuanes, el paisaje de los campos y aldeas incultas, cerrando lo ojos a la luz de la civilización y de la libertad, y armándose de palos de guadañas para defender su secular igno rancia y pobreza estacionaria, sin que por eso nuestros gau- 
chos, como los chuanes franceses, gritasen viva el rey absoluto, ni siguiesen a los párrocos como generales. La montonera no pudo ser metrallada, exterminada como la chuaneria; porque era más digna de vivir y menos torpe en sus fines, y ha vivido treinta años, merced a la anchura infinita del desierto que da ba amplitud a sus movimientos, como libertad e independencia semibárbara a sus masas." (XV, 393). Y Sarmiento, convencido de la legitimidad del parangón, se pregunta cómo los franceses no comprendían nuestra lucha entre civilización y barbarie, só lo porque se hubiese prolongado más que aquella terminada con la pacificación de la Vendée, y no por la república triunfante sino por el despotismo renaciente.

Francia, la Revolución, y sus consecuencias, son temas de interés permanente en Sarmiento, con distinto motivo y tratamiento. En este orden de cosas, debe apuntarse el conocimien to y la ponderación admirativa de los hombres que con su pensá miento y sus obras hicieron pasible la Revolución. Sarmiento ve en los enciclopedistas, especialmente en Voltaire, y más aún én Rousseau, a los verdaderos fautores del cambio, a los heraldos que supieron "profetizar el próximo temblor que iba a echar por tierra el ruinoso y gótico edificio social" (IV, 241). Y por eso repite admonitoriamente las palabras de Edgard Quinet: "Sin Montesquieu, Voltaire, Rousseau, Buffon, ¿qué que da del siglo XVIII? Quitadle a la Revolución los hombres ilustres, ¿qué queda? Un pueblo mudo y predispuesto a la servidumbre." (XXXVIII, 12)

Contrariamente a esa admiración por los filósofos, reprueba y estigmatiza la falta de escrúpulos, traición de ideales o despotismo de los verbosos tiranuelos de turno, Marat, que "pedía cabezas de tiranos por millones!" (LII, 36), Danton, predicando "audacia, más audacia, y siempre audacia" (LII, 30), Robespierre, haciendo "su terrible papel de furibundo por patriotismo" (XXXVIII, 347), la violencia y la injusticia para asegurar la paz y la fraternidad.

En fin, Francia y sus conmociones se hacen presentes a raíz del conflictivo (hoy reactualizado) tema de "la capital de la república". Corre el año 1860. Sarmiento, partidario de que ella no se instalase en la populosa ciudad que era ya en- 
tonces Buenos Aires (!), argumenta con lá tesis histórica y ge neral de que la libertad había sucumbido cada vez que una metrópoli rodeaba al Poder, quedando "dominada la representación nacional por la población de la ciudad capital" y las provincias con la misma suerte. En su diatriba, Sarmiento apela al ejemplo de la Revolución Francesa, recordando "que la asamblea constituyente, arrastrada a París desde Versalles por un movimiento popular, había sido bien pronto dominada por la Comuna de París, a la cual tuvieron fácil acceso Danton, Marat, que con los arrabales dominaron la Convención." (XIX, 35). Para re cordar lo que sucedía en torno de tales preocupaciones, basta con leer a Michelet que muestra las luchas entre federación y monarquía primero, entre federación y unidad republicana después. En medio del debate, lo que está en juego es la hegemonía de París. El célebre historiador recuerda que "Condorcet, en un admirable opúsculo, afirma que París era el instrumento de esta unidad", mientras que Desmoulins advertía: "¿París, Pa rís, cuidado que no adviertan tu conducta'en los departamentos!... i Tú necesitas de ellos para existir; ellos no necesitan de ti para ser libres!..." (22)

Hemos señalado también su reserva fundada en el popu 1ismo. Si algo lo exasperaba era el uso abusivo y demagógico de la invocación al pueblo. La palabra, tan usada y maltraída por mezquinos intereses politicos no le gustaba. Desconfiaba de ella, la subrayaba constantemente en señal de protesta. Su invariable prédica en defensa de las instituciones republicanas hacía hincapié en la representatividad como instrumento idóneo de la soberanía popular. Recordaba con insistencia que el pueblo no gobierna por si mismo sino a través de sus representantes. Aquella intervención abrupta del pueblo en los acon tecimientos de la Revolución Francesa lo indisponía, lo sublevaba. No toleraba, especialmente, que en su nombre se vulnerasen los derechos naturales de la persona: "Sacrifíquense los derechos individuales para salvar la nación y la integridad del territorio francés por las matanzas de setiembre. Asi vino la tiranía que pesó sobre el mundo europeo." (XIX, 29)

Por el contrario, él mismo enunciaba lo que debía enten derse por pueblo, con definición objetiva y limitada: una so- 
ciedad capaz de gobernarse a partir ae la soberania, y segun las leyes; con restricciones que son al mismo tiempo garantías provenientes de la naturaleza humana, y que constituyen los derechos naturales. Sarmiento los enumeraba: "el de no ser pri vado de la vida, la libertad o de la propiedad, del honor o de la facultad de comunicar sus pensamientos o deseos, sino bajo ciertas formas establecidas, en virtud de una ley escrita, y oído el acusado de infracción de la ley, antes de aplicarle la pena que es la sanción de esa ley." (XXXIX, 6) ¿Qué es esto, sino una apretada síntesis de los derechos del hombre y del ciudadano, sancionados en 1789?

En fin, para Sarmiento, la Revolución Francesa termina desvirtuada en su derivación: Napoleón, cuya espada "pesó por el espacio de catorce años sobre la nación", "enfrenando la Re volución", invadiendo países, suprimiendo libertades, coronándose Emperador. 0 sea, lo constante en las luchas revolucionarias, que Sarmiento traza con pluma terminante asi: "Estas tentativas de cambio se organizan poco a poco;de principios pa san a ser hombres; de hombres pasan a ser partidos; de partidos pasan a ser ejércitos; de ejércitos pasan a ser gobierno y poder. La necesidad del ataque y de la defensa, va concentrando lenta e insensiblemente todos los intereses de la acción y de la reacción en una mano, así es que apenas se realiza el triunfo de alguna de las dos fracciones contendientes, se ve surgir a un hombre poder en quien vienen a encarnarse todos los elementos de acción y todas las ideas que desparramadas en el sentir general de la época dieron principio al choque. Por esto es que todas las revoluciones acaban por elevar un dominador, es decir, un hombre centro que resume y reduce a po der real todos esos principios e intereses que empezaron como teorías a atacar los poderes preexistentes. He aquí por qué do minó Napoleón." (II, 115)

La Revolución Francesa había sido, según Sarmiento (con neta diferencia de otras interpretaciones), traicionada por Bonaparte, al conducir por un camino de gloria "la Francia a la desmembración y al oprobio" (XXXIX, 32). En suma, Sarmiento ve a la empresa napoleónica como una gran paradoja de la histo ria: de una parte, representó la negación en la práctica dé 
muchos de los principios revolueionarios: "al observar su lar- silencio, la quietud aparente de superficie de aquella sociedad que parecia toda consagrada a la victoria y a las armas, hubiérase dicho que la revolución había cesado y que había pactado con los acontecimientos" (VI, 4). Y de otra, fue 1a gran ocasión para los pueblos de América empeñados en su emancipación, "puesto que a Fernando el querido le echaba la zarpa en Bayona, y lo contemplaba con curiosidad, como el gato a la laucha que tiene bajo su garra." (XXVIII, 201)

No le faltaba humor cuando queria, para referirse al Em perador. Hablando de Los gallos literarios (Mercurio, 23-61842) dice: "El gallo francés es igualmente bizarro, y tan altivo que sólo gusta posarse en lo alto de las banderas y en la parte superior del escudo de armas de su nación. Un tiem po hubo en que cedió su puesto a un águila formidable; peró los gallos insulares cayeron sobre ella, la maniataron y la condujeron a una ínsula remota, en donde murió la triste encadenada a una roca."

Consecuente con su capital preocupación, Sarmiento ejer citó, más que un análisisis de los acontecimientos históricos o de las ideas políticas inherentes a la Revolución Francesa, un análisis de ella en relación con la educación. Destacaba sus falencias, señalando reiteradamente que hacia 1789, en Francia, la mayoría del pueblo y aún los Corregidores no sabían leer, y llegaba osadamente a oponerles nuestra situación, afirmando: "Véase por el número de escuelas de diez años antes en Buenos Aires, que hasta los porteros podían firmar un recibo." (XXVIII, 202). No tuvo, pues, demasiado en cuenta (pero eillo fue comín durante mucho tiempo) las realizaciones: 1a Convención Nacional, especialmente en su último tiempo, elaboró un proyecto de enseñanza primaria gratuita y obligatoria, escuelas secundarias gratuitas (otras de paga), creó las grandes escuelas, Normal Superior, (para formar profesores), Politécnica (para formar ingenieros y oficiales), Puentes y Caminos, de las que salieron los cuadros superiores de la nación durante un siglo y medio; fundó el Conservatorio de Artes y oficios y el Museo de Historia Natural; reorganizó los antiguos colegios, recomendan do enseñar en ellos "menos latín y más ciencias". (23) 
Sarmiento ponderaba, sin embargo, la literatura del siglo XVIII, "tan polémica y tan contundente en sus golpes, que el ruido y el murmullo de las voces irritadas llegaba hasta las profundidades de la América" (XXVIII, 200). El gran 11bro (aparte de Robinson Crusoe, del que tan elogiosamente y tantas veces habló) fué para él Emilio. Pero sobre todo, aunque disintiese con ciertos aspectos de la Revolución, no podía dejar de coincidir con la plena reivindicación de los derechos "naturales" con el "pragmatismo" propugnado en la enseñanza, porque ésta era la nueva educación que se oponía a la antigua y tradicional, eminentemente abstracta, retórica y teologal.

Si ha habido para la Revolución Francesa las explicacio nes más peregrinas, hasta llegar a vérsela como hija de la explotación de oro del Brasil, no podía faltar alguna de este tí po en Sarmiento, conocido por ciertas interpretaciones y pasa jes disparatados pero divertidos según los califica Anderson Imbert, como aquel que pretende que "a los españoles que leian 1a Araucana en las ciudades les puso miedo el relato, como a los niños los cuentos de brujas, y los reyes de España mandaron cesar el fuego", o la explicación de las tonadas por "la marcha de las cabalgaduras, haciendo acentuar la palabra al asentar el caballo la pata", o aquel otro en que imagina al Vi rrey Toledo contándole a Víctor Hugo su terror de la Inquisición (24). Como una más de estas sorprendentes extrapolaciones (por llamarla de algún modo) mencionemos la de que los males de la Revolución Francesa se deberían a...las lenguas clásicas, al latín y al griego. Oigámoslo: "Al fin, el latín y el griego trajeron la más espantosa tragedia de los tiempos moder nos, cual fue la revolución francesa y su pobre desenlace, dejando burlada a la humanidad, después de haber inmolado lo más noble del pueblo francés. ¿Quiénes lanzaron la revolución en la falsa vía que tomó? -Sieyes, Talleyrand, Vergniaud, Robespierre, Mirabeau, la Roland, Camilo Desmoulins, latinistas que se 11 amaron Arístides, Scipion, Focion, Graco,Caton. César estaba siempre, según ellos, amenazante a la puerta de la Asam blea, hasta que un estudiantillo de genio, con los Comentarios de César en el bolsillo, realizó el tipo ideal paseando por tó da la Europa las águilas romanas a la cabeza de las legionés 
de un César corso," (Xax, 120). A tan diversas causas se han atribuido los excesos de la revolución Francesa, que la explicación de Sarmiento no ha de pesar demasiado en la balanza de los historiadores. Sí, seguramente, en la de los helenistas y latínistas que no se la perdonarán (sin contar a los fanáticos de Napoleón).

$\infty 0$

Faltaban unos pocos meses para el primer Centenario de la Revolución Francesa cuando murió Sarmiento. De haber sobrevivido, seguramente habria escrito algunas páginas de homenaje, como lo hiciera en ocasión del Centenario de la Independen cia de los Estados Unidos (con motivo del brindis en la casa del Ministro General Osborn, el 4 de julio de 1876). En dos aníversario del 14 de julio habia estado en Francia, en 1846 y 1847. El prịmero lo pasó en Versalles, el segundo en París. ¿Qué hịzo en cada uno de esos días? Aparentemente nada que tuviese relación directa con la efemérides, al menos si juzgamos por su Diario de gastos. No pudieron, obviamente, transcurrirle indiferentes, pero ninguna anotación lo registra. Curioso, perceptivo, infatigable, ¿qué paseos o itinerarios habrá hecho, que no conservan sus notas? De su estada en París nos quedan dos testimonios de primer orden: el mencionado diario y la car ta arsu amigo Aberastain.

Flâneur impenitente, el mismo ha contado las delicias de sus vagabundeos, haciendo el elogio de la flânerie: "Ando lelo; paréceme que no canino, que no voy sino que me dejo ir, que floto sobre el asfalto de las aceras de los bulevares". Paseaba, con el plano de París que había comprado, extraviándose, preguntando, descubriendo asombrado "que sólo en Francia y sobre todo en Paris se encuentra esa benevolencia pública, esta bondad fratermal. Sólo on París también el extranjero es el dueño, el tirano de 1 a ciudad. Museos, galerias, palacios, nonumentos, todo está abierto para él,menos para el parisiense, 
a toda hora $y$ en todos los días. Mostrar su pasaporte a la puerta es mostrar un firman ante el cual se quita el sombrero el conserje", para terminar conmovido ante la urbanidad y cortesía del pueblo francés, que lo lleva a preguntarse si ese pueblo tan solícito $y$ afable es el mismo que hiciera las revoluciones de 1789 y 1830: " $i$ Imposible! Y sin embargo, ello es real." ( V, 117)

Sabemos que fue al Luxemburgo, al Barrio latino, a Boulogne, al Hipódromo, al Jardin des Plantes, al Champ-de-Mars, al Café de París, al Palais Royal, al baile Mabille, al Ranelagh....según lo que registra. ¿Y lo que no registra? ¿Habrá llegado en sus paseos hasta la Bastilla, uno de los barrios más populares de París? Si lo hizo, pudo contemplar la Columna de Julio, terminada poco antes y -tal vez- la maqueta de la fuente que en forma de elefante había proyectado Napoleón, abandonada alli hasta 1847 .

En el Bicentenario, lo imaginamos andando por el "París encantado de la Francia de nuestros sueños, como él decía, pasando por los lugares más memorables de los fastos revolucio narios, evocando con su imaginación siempre vivaz y colorida, figuras y episodios del pasado francés.

De aquel grato séjour y del contacto con las gentes guardaría un recuerdo definitivamente vivo y actuante. De la Revolución, y a pesar de sus reparos, destacaría cada vez, en adelante, el logro imprescriptible de los Derechos del hombre y del ciudadano, el culto de los pensadores que los alumbraron, y el carácter intemporal y universal de su legado.- 
1.- Raúl A. Orgaz, "Ensayo sobre las revoluciones", en Sociologia, Córdoba, Alessandri, 1950, p. 357.

2.- Todas las citas de Sarmiento corresponden a las Obras completas, ed. de Augusto Belin Sarmiento. Los números rómanos indican el tomo, los arábigos la página.

3.- Paul Hazard, La pensée européenne au XVIIIe. siècle, Pa ris, Boivin, 1946, p. 373 .

4.- Ib., p. 374 .

5.- Georges Duby y Robert Mandrou, Historia de la Civilización Francesa, F.C.E., México, 1966, p. 328.

6.- J. Ortega y Gasset, "Prólogo a la Historia de la Filoso fía de Karl Vorländer", en Historia como sistema,Madrid, Revista de Occidente, 1941.

7.- Citado por Orgaz, op. cit., p. 375 .

8.- Orgaz, op. cit., p. 348 .

9.- A. Camus, L'Homme révolté, Paris, Gallimard, 1952, p.136.

10.- J. Huxley, Vivimos una revolución, Bs. As., Sudamericana, p. 17 .

11.- Ortega y Gasset, "El ocaso de las revoluciones" en EI tema de nuestro tiempo, Madrid, Revista de Occidente, 1961, p. 109.

12.- Orgaz, op. cit., p. 359.

13.- Camus, op. cit., p. 136

14.- Orgaz, op. cit., p. 359.

15.- O. Paz, El arco y la lira, México, F.C.E., 1981, p.220.

16.- G. M. Trevelyan, La Revolución inglesa, México, F.C.E., 1951 , p. 7.

17.- A. Maurois, Historia de Inglaterra, Bs.As., Hachette, 
1966, p. 216 .

18.- Crane Brinton, Aniatomía de la Revolución, Madrid, Aguilar, 1958.

19.- Ortega y Gasset, "El ocaso de las revoluciones", op. cit., p. 109.

20.- Boletín de la Academia Nacional de la Historia, Vol. XIII, Bs. As., 1940, p. 159.

21.- Camus, op. cit., p. 25.

22.- J.Michelet, Historia de la Revolución Francesa, Bs. As., Argonauta, 1946, t. III, p. 15.

23.- Cf. E. Lavisse, Histoire de France, Paris, Colin, 1935, p. 281 y Duby-Mandrou, op. cit., p. 396.

24.- Cf. E. Anderson Imbert, Genio y figura de Sarmiento, Bs. As., Eudeba, 1988, p. 154 . 